\title{
The Construction of a Five-dimensional Model of Postgraduate Ideological and Political Education*
}

\author{
Xiaoyuan Wang \\ School of Machinery and Automation \\ Wuhan University of Science and Technology \\ Wuhan, China
}

\author{
Ming He \\ Graduate School \\ Wuhan University of Science and Technology \\ Wuhan, China
}

\begin{abstract}
In talent training system of higher education in China, postgraduate training is at the highest level and an important force for social progress. Postgraduate ideological and moral education is a significant part of the process of postgraduate training. It occupies an important position in the postgraduate education system in colleges and universities, and directly affects the quality of postgraduate training. How to do a good job in postgraduate ideological and moral education is not only a major task that university workers urgently need to solve, but also a very forward-looking and great challenge.
\end{abstract}

Keywords-five-dimension; postgraduate ideological and moral education

\section{INTRODUCTION}

The profound changes in international and domestic situation, in-depth development of socialist market economy, expansion of the university-running scale, and new changes in the training mode and management mode have made postgraduate ideological and political education face both favorable conditions and severe challenges. A rolling survey of the ideological and political situation of college students in 2016 shows that the mainstream of college students' ideology is positive, healthy and upward. However, affected by social trends and campus "subculture"[1], the ideological and moral education, ideals and beliefs and other mainstream ideologies of postgraduates have changed and transformed obviously under the new situation. Some postgraduates still have some problems, such as confused political belief, vague ideals and beliefs, distorted value orientation, lack of social responsibility and corruption of academic morality, mainly summarized as follows.

*A. Wuhan University of Science and Technology 2018 Postgraduate Quality Project "Study on the "4+1" Collaborative Innovation Model of Ideological and Moral Education for Postgraduates in the Background of Construction of "Double First-rate" Universities and Colleges" (Project No.: Yjg201810)

B. Hubei Province's 2017 College Practical Education Featured Project "Steel Spirit Theme Education for Postgraduates and Moral Education Practice Innovation in Metallurgical Colleges" (Project No.: 2017SJJPC3010)

C. Wuhan University of Science and Technology 2017 Postgraduate Quality Project "Exploration and Practice of Practical Education System for Full-time Professional Degree Postgraduates" (Project No.: Yjg201722)

\section{A. Weak Ideological and Moral Concepts and Diversified Development Trends in Values}

Some postgraduates' moral views and ideologies lack stability, and they lack the ability to distinguish right from wrong. With the popularity of new media, a large amount of information emerges and the quality of online information varies. As the main user of new media, postgraduates are more vulnerable to some bad customs including money worship, hedonism and individualism spread by western hostile forces. Especially for postgraduates of science and engineering, they only lay stress on the study of professional theory, and neglect the improvement of ideological and moral quality, which is easy to cause weak ideological and moral concepts.

\section{B. Increasing Mental Health Problems}

Psychological problems are manifested in the form of morality, and moral behavior can reflect people's psychological problems. People's moral character affects their mental health. In recent years, there have been a series of incidents in which postgraduates commit suicide or crime due to psychological problems. Related statistics show that the incidence of psychological disorders or mental diseases of postgraduates is increasing year by year, and the mental health problems of postgraduates have gradually become the main problem of postgraduate education in colleges and universities.

\section{Weak Credit Consciousness and Outstanding Academic Morality}

Some postgraduates have academic misconduct and serous plagiarism. In recent years, the plagiarism of postgraduate papers has emerged in endlessly, and the credit crisis of postgraduates has sounded an alarm to the ideological and moral education of postgraduates in colleges and universities. The academic immorality and academic misconduct of postgraduates have adversely affected the quality of talent cultivation in the country, society and universities.

\section{PREDICAMENT OF IDEOLOGICAL AND MORAL EDUCATION OF POSTGRADUATES}

\section{A. The Construction of the Teaching Staff Is Not Comprehensive Enough}

At present, the construction of postgraduate ideological and moral education team in colleges and universities is not comprehensive, and the level of business needs to be improved. In terms of full-time working team for postgraduate 
ideological and moral education, most of the current university counselors have a master's degree, and some even have a bachelor's degree. What's more, the subjects they studied in university are not coincident with the subjects of ideological and moral education [2], resulting in the problems of low theoretical level and lack of practical experience in ideological and moral education. As for social science teaching staff, their understanding of development and changes of domestic and foreign situations and ideological situation of postgraduates is not deep enough. The teaching content is monotonous, empty and not timely. For postgraduate tutor team, postgraduate tutors generally "attach importance to wisdom rather than morality". They often pay too much attention to postgraduates' scientific research level and scientific achievements, and neglect the guidance of postgraduates in ideology and morality.

\section{B. The Construction of Network Education Position Is Not Extensive Enough}

At present, the position of network ideological and moral education is confined to QQ space, WeChat Moments and other basic social software by the ideological and political working team in colleges and universities. However, postgraduates' information acquisition is more timely and wide-ranging, and their expression space keeps expanding. As a result, the timeliness of ideological and moral education is not high and the dimensions are not wide.

\section{The Foundation of Family Education Is Not Solid Enough}

Parents are the best teachers for their children, and their words and actions affect the development of ideology and morality of postgraduates from beginning to end. Some postgraduates' parents are not highly educated and affected by unhealthy social trends to different degrees, and then imperceptibly influence the development of postgraduates' correct ideology and morality through their own words and deeds, resulting in the weak foundation of postgraduate ideological and moral education, which imperceptibly adds resistance to the ideological and moral education in colleges and universities.

\section{Social Planning and Coordination Construction Is Not Enough}

The main activities of university postgraduates are concentrated on the campus. It is common in society that the postgraduate ideological and moral education is only the main responsibility of colleges and universities. Moreover, all sectors of society do not pay enough attention to and support the postgraduate ideological and moral education, and do not fully coordinate and supervise the postgraduate ideological and moral education in colleges and universities, which cannot form the greatest resultant force of universities, families and the whole society and draw the largest concentric circle

\section{E. The Self-Education Mechanism Is Not Sound Enough}

Self-education mechanism includes internal mechanism and external mechanism [3]. The internal mechanism is for the subject of self-education. Postgraduates' self-education in ideology and morality is the moral cultivation of postgraduates under the dual impetus of self-development requirement and social development requirement. Self-education of postgraduates emphasizes postgraduates' subjective consciousness. It has some problems such as unscientific establishment and construction of party branches, non-standard class management, and incomplete mutual assistance among peers, affecting the soundness of internal mechanism and the play of good role. The role of external mechanism is to guide and help postgraduates, and promote their enthusiasm for selfconstruction in ideology and morality. It mainly has the problems of the lack of wide example setting and guidance, unclear goal guidance and shallow value guidance. The above problems have formed resistance to the improvement of postgraduates' self-education mechanism in ideology and morality, and have adverse effects on the establishment of a long-term mechanism.

\section{CONSTRUCTION OF A FIVE-DIMENSIONAL MODEL OF} POSTGRADUATE IDEOLOGICAL AND POLITICAL EDUCATION

\section{A. Speeding up the Construction of Teaching Staff of Moral Education}

The first is the ideological and political work team. This is the backbone of postgraduate ideological and moral education. We should strive to build a team with high academic level, high ideological and political quality, strong career aspiration and a certain level of ideological and moral education. What's more, universities should care about them in politics, study, work and treatment. The second is social science teaching staff. Social science teachers must have a thorough understanding of the development and changes of the situation at home and abroad, understand the ideological situation of postgraduates, constantly reform the teaching content, and change the simple and empty "instillation" method in the past, and conduct multiangle, multi-faceted, multi-channel and multi-form education for graduate students. The third is postgraduate tutor team. Postgraduate tutors play a central role in the process of "people's cultivation based on teaching, management and service". The moral cultivation, academic attitude and academic level of tutors affect students in an invisible way. The noble teaching morality is a good textbook, which has a subtle, profound and lifelong impact on students. Therefore, we must work hard to build a group of tutors with good quality, excellent professional ability and strict style.

\section{B. Strengthening the Construction of Network Education Field}

With the increasing maturity of Internet technology and the popularity of mobile phones and computers, graduate students have access to information timely and widely. Moreover, their expression room has been expanding continuously. Accordingly, an excellent utilization of the new media platform helps to achieve the ideological education guidance for graduate students. It's necessary for the postgraduate ideological and political education workers in colleges and universities to fully integrate the resources inside and outside the school to build a postgraduate ideological and moral education position with the characteristics of their own university regarding the network as the link, and to carry out the postgraduate ideological and moral education practice activities in an organized and planned manner. First, strengthening the construction of network education fields demands the attention to the diversification of online education methods. The ideological and political education of 
contemporary graduate students should be based on the education concept of "infiltration" rather than the "indoctrination". In order to improve the effect of postgraduate ideological and political education, "educators should make full use of the advantages of Internet, such as richness in information, vividness in sound and image, convenience in connection so as to make the network ideological and political education vivid, intuitive and interesting according to their demands"[4], which asks for the realization of diversified spread of educational methods. It's wise for colleges and universities to make full use of BBS, WeChat, Weibo, QQ and other self-media to carry out postgraduate ideological and political education in virtue of film strip, online interaction and other diversified ways. Second, it's advisable to pay attention to the enrichment of online education content. The establishment of ideological and political education to meet the individual growth of graduate students is the development needs of the network era. The content of online education should combine the postgraduate ideological and political education with the service. Creating a network that graduate students would like to surf and teachers teach through lively activities should convey the mainstream thoughts and correct social norms and values to students subtly, achieving the transformation of education concept from "indoctrination" to "infiltration". Therefore, the network content of postgraduate ideological and political education in colleges and universities should not only involve basic postgraduate ideological and political education, integrate social core values into the online education platform to guide graduate students to establish correct values, outlook on life and world view, but also should be close to the actual life of graduate students to meet the development of their personalities. In response, it's necessary to increase the content of psychological education, rule of law education, academic moral education, and ethics education in the network education platform to increase the selectivity for graduate students and broaden the knowledge of students. Third, the network education supervision should be normalized. Postgraduate moral education workers shall keep an eye on the use of graduate students' media platforms to timely understand their ideological trends. It's of great significance to comprehensively supervise the ideological and ethical status of graduate students by means of media platform, and enhance consensus and unify thoughts by promoting policies and resolving doubts on platforms so as to control the moral and ethical status of graduate students within reasonable expectations.

\section{Strengthening Family Education Foundation}

First, improve the quality of family members themselves. Family members should strengthen their ideological and moral cultivation, and educate their children with scientific educational concepts and methods to endow them with a correct world view, outlook on life and values. At the same time, it's important for family educators to often communicate with children. Making friends with children, understanding children's thoughts and learning dynamics, improving the quality of family members, and implementing positive ideological and moral education for children is the core of current family education. Second, universities should strengthen the study of postgraduates' family education. At present, the research on their family education is still in a blind state. There is neither a unified organization nor a theoretical guidance of systematic science. Marxist theory points out that "genuine knowledge comes from practice", and in fact, theory is also counterproductive to practice and can guide practice. In order to enhance the theoretical guidance level of family education, colleges and universities should actively carry out research on family education issues, investigate and analyze the status quo and problems of graduate family education, and then, propose corresponding solutions on this basis. Therefore, colleges and universities should actively carry out research on family education issues, so that the guiding theory of family education advances along the path of scientificization. Third, establish a sound communication platform between family and school. It's advisable to use modern network technology to build a network home-school cooperation platform, so that family education and college ideological and political education can be combined through network. In addition, it's wise to establish a "parent-school exchange platform" to integrate campus culture with rich educational resources so as to build up a network platform with rich information, obvious features, and strong intelligent interactivity. Fourth, build a social support system for family education. It is not enough for the university students' education just by relying on the strength of the family and the school and it must also receive the attention and support from the society. The relevant departments of the society must create a good social environment, so that students can experience different social roles in a complex social environment, and enhance their analytical and strain capacity. In addition, the government can set up classrooms for off-campus parents to let them understand the importance of family education. The classrooms bear the responsibility of training and educating parents, advocating scientific and effective family education methods, making parents correctly understand the laws of human development and the psychological process of children to make them a qualified parent.

\section{Forming a Society-wide Participation and Coordination Linkage Mechanism}

The problems of postgraduate ideological and moral education are difficult to solve only by the power of the school. In the mean time, it requires the joint attention and strong support of the Party and the government as well as the whole society. In particular, the Party committees at all levels and the government departments in charge of propaganda and education must strengthen the overall coordination and supervision of postgraduate ideological and moral education and assist universities to solve the practical problems of postgraduates in study, life, employment, etc. to promote the work implementation of postgraduate ideological and moral education. At the same time, the grassroots party organizations in colleges and universities should play an exemplary vanguard role, and the graduate party members should act as examples in morality, thus promoting the improvement of the overall moral quality of graduate students. Social public opinion should carry out propaganda with the core of social mainstream values, and criticize accompanied by correcting the bad atmosphere of society. Only the joint efforts of the Party, the government, the society, the university, the family, and the graduate students can form the greatest synergy and 
promote the improvement of the ideological and moral quality of graduate students.

\section{E. Improving the Self-education Mechanism}

For the internal mechanism, the first is to strengthen the class management. The class is the organization that has the closest contact with students. The education and management of students by the class is to raise a series of requirements for postgraduates and provide methods for managing the students, and the class can serve as the bridge and link for the mutual understanding and communication between schools, colleges and students. Students can communicate their wishes and thoughts to schools and colleges through the classes, creating conditions for their better development. The second is to strengthen the mutual help among peers. The mutual help among postgraduates will enable the students to improve themselves in a larger space and in a larger scope, promoting them to develop their own abilities more comprehensively. Everyone's living experiences and knowledge are different. The exchange of experience between postgraduates can make them resonate with each other to a certain extent and form the atmosphere of making progress together. The third is to strengthen the construction of university clubs. Although the university club is not so direct and targeted compared with the class, it is also an important driving force for the development of postgraduates' self-improvement and self-moral education. Compared with the class, the university club plays a more important role in improving postgraduates' ability of mutual cooperation and giving play to postgraduates' subjective initiative, developing the organizational coordination capabilities of postgraduates. For the external mechanism, the first is to strengthen the leading role of models. The driving power of models is great. The models have important guiding significance for motivating postgraduates to conduct ideological and moral self-education. They can mobilize the enthusiasm of postgraduates for learning. The second is to strengthen the goal guidance. In view of the weak psychological will of postgraduates, the state, society and schools should set an overall goal for postgraduates' selfideological and moral education. The third is to strengthen value guidance. As the trend of internationalization is becoming more and more obvious, postgraduates are increasingly exposed to Western cultures, and some postgraduates are affected by Western harmful cultures. In order to guarantee the correctness of ideological and moral values of postgraduates, it is necessary for us to guide the values of postgraduates in their self-education.

\section{CONCLUSION}

With the continuous deepening of the construction of socialist modernization, the status and role of ideological and moral education for postgraduates has become more apparent. Especially in the face of the new situation of reform and opening up and the complex social environment, we should pay attention to the research on the theories and practices of ideological and moral quality education for postgraduates standing at the height of concerning about the future and fate of China, constantly exploring new working ideas, innovating working methods, constantly discovering new situations, studying new issues, solving new problems, and cultivating high-quality talents with both ability and political integrity for the construction of socialist modernization.

\section{REFERENCES}

[1] Ye Dayang. Campus Subculture Challenge to Ideological and Political Education and the Countermeasure Analysis[J]. Journal of Heilongjiang Vocational Institute of Ecological Engineering, 2018(1):97-99.

[2] Huang Kai. On the homogeneity of education in ideological and political education and the cultivation of correct values of college students[J].Journal of Suzhou Education Institute , 2016, 19(3):75-76.

[3] Zheng Man. A brief analysis of self-thought moral education of university graduate students[J]. Charming China, 2017(43).

[4] Li Fan, Li Decai.Thoughts on the innovation of education method in network ideology and politics[J]. Journal of Ideological \& Theoretical Education, 2012(6): 102-105.

[5] Wang Jufang, Zhi Yao.Current situation and countermeasures of the influence of network on education of graduate students' ideological politics[J]. Academic Degrees \& Graduate Education, 2007(11): 55. 